\title{
A história da álgebra e o pensamento algébrico: correlações com o ensino
}

\author{
FLÁVIO ULHOA COELHO ${ }^{I}$
}

e MARCIA AGUIAR II

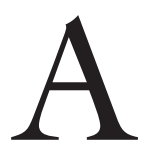

ÁlgEBRA faz parte do desenvolvimento humano e, como tal, surge inicialmente para resolver necessidades práticas, estando bastante presente em nosso cotidiano de várias formas. Por isso, e como não poderia deixar de ser, ela é parte essencial no ensino de Matemática nos níveis Fundamen-tal e Médio. Reconhecendo a sua relevância na formação do cidadão, em 20 de dezembro de 2017 foi homologada a Base Nacional Comum Curricular $(\mathrm{BNCC})^{1}$ que apresenta em seus documentos que a Unidade Temática Álgebra seja desenvolvida desde os anos iniciais do Ensino Fundamental. Na prática, porém, o ensino-aprendizagem da Álgebra tem gerado algumas deficiências que são diagnosticadas em várias pesquisas e nas avaliações governamentais. Acreditamos que isso ocorre em vista da ênfase que se dá a seus aspectos técnicos, deixando de lado, muitas vezes, o desenvolvimento dos conceitos e uma busca por um pensamento mais abstrato. Acreditamos que ao se enfatizar o pensamento algébrico ao invés de apenas se restringir a questões técnicas e operacionais, o ensino de Álgebra poderia contribuir não só no aprendizado da Matemática como também auxiliar no desenvolvimento do pensamento lógico-abstrato do estudante, pensamento esse essencial para o desenvolvimento de um cidadão capaz de viver na sociedade atual.

Ao se olhar para a história da Álgebra, desde os primórdios quando o objeto de estudo eram equações algébricas específicas até o estabelecimento de uma área de pesquisa que hoje é essencialmente abstrata (se levarmos em conta muitos dos problemas considerados atualmente pelos pesquisadores), perceberemos um longo caminho de busca de padrões e sedimentação teórica.

Essa mesma história nos ensina como aconteceu o difícil estabelecimento dessa área de conhecimento. Houve a necessidade da construção de uma linguagem simbólica apropriada às questões tratadas aliada à consequente emersão de conceitos algébricos cada vez mais abstratos. Só assim a Álgebra se consolidou como área de conhecimento, área essa que é, portanto, fruto de um desenvolvimento histórico e não inata ao ser humano. Dito de outra forma, o conhecimento da Álgebra precisa do meio social para ser aprendido e assimilado pelo 
indivíduo. De acordo com a nossa estrutura social, esse ensino compete à escola ou, mais especificamente, à disciplina de Matemática.

Nosso objetivo aqui é apresentar certos recortes sobre esse desenvolvimento histórico a partir de relatos de alguns historiadores da matemática e compreender qual conceito algébrico estava explícito ou implícito nesse citado percurso.

A partir dessa compreensão, pretendemos identificar desenvolvimentos históricos que podem ou não ser utilizados no processo de ensino da Álgebra, não esquecendo que estamos buscando um ensino que enfatize mais a forma de pensar do que a mera resolução de exercícios.

Assim, estamos interessados em responder a seguinte pergunta: De que forma a compreensão do desenvolvimento da história da Álgebra ao longo dos tempos pode nos dar subsídios para repensarmos o processo de ensino-aprendizagem do ensino de Álgebra na Educação Básica?

Esse trabalho originou-se durante o ano sabático do primeiro autor junto ao Instituto de Estudos Avançados da USP no ano 2016, que deixa registrado aqui seus agradecimentos ao apoio institucional recebido do IEA durante esse estágio de pesquisa.

\section{A Álgebra sob o âmbito escolar}

Há algumas décadas, as avaliações governamentais apontam possíveis deficiências no aprendizado da matemática, em especial no da Álgebra, como podemos verificar em Silva (2008), que apresenta dados estatísticos do desempenho dos alunos em matemática no SAEB-2003. Da mesma maneira, Ribeiro (2001) analisa o desempenho de estudantes do Ensino Fundamental em Álgebra, com base em dados do Saresp.

Outras pesquisas, igualmente, também indicam as dificuldades apresentadas pelos estudantes na aprendizagem da Álgebra (Lins; Gimenez, 2001). Essas constatações não ocorrem apenas no Brasil, mas também em muitos países. Citamos como exemplo o $12^{\circ}$ ICMI Study ${ }^{2}$ em 2001, que foi dedicado ao ensino de Álgebra e falou da necessidade de desenvolver nos estudantes a capacidade de abstração (Stacey; Chick, 2004). Encontramos pesquisadores que discutem e investigam sobre as deficiências no ensino e aprendizagem da Álgebra (Blanton; Kaput, 2005; Kaput; Blanton; Moreno, 2008; Ribeiro; Cury, 2015; Wasserman, 2016).

Os resultados que a aprendizagem da Álgebra vêm apresentando nas últimas décadas provêm, na verdade, de um processo que o ensino dessa área vem sofrendo ao longo dos anos e que se mantém em voga na escola atual. No Brasil, mesmo com várias reformas educacionais, novas diretrizes e orientações propostas para o sistema educacional, o ensino de Álgebra permaneceu com poucas alterações na Educação Básica. Muitos pesquisadores afirmam que, no ensino de Álgebra, ainda prevalece a aprendizagem de um conjunto de técnicas operatórias que busca apenas resolver equações sem contextualizá-las, porém (Barbosa; Borralho, 2009; Aguiar, 2014). 
Nesse cenário, cabe questionarmos se o ensino atual está proporcionando aos estudantes uma aprendizagem de fato. Para entendermos essa situação, não basta olharmos apenas para o momento atual e, sim, compreendermos como o ensino de Álgebra se desenvolveu ao longo dos tempos e quais as concepções que permearam esse caminho. Para isso, apoiamo-nos em Fiorentini, Miguel e Miorim (1993) que procuram descrever cada momento do desenvolvimento do ensino de Álgebra.

De acordo com Fiorentini, Miguel e Miorim (1993), há, ao menos, três concepções com características distintas que influenciaram esse ensino de forma significativa.

Em primeiro lugar, esses autores destacam o chamado transformismo algébrico que foi a base do ensino de Álgebra, tanto no Brasil quanto em outros países, durante todo o século XIX e a primeira metade do século XX. Entende-se por isso o processo de obtenção de expressões algébricas equivalentes entre si mediante o emprego de regras e propriedades válidas, resultando, em última instância, em um mero jogo, muitas vezes artificial, de habilidades visando a resolução de problemas. Acreditava-se que isso fosse o suficiente para que o aluno adquirisse a capacidade de resolver problemas, problemas esses na maioria das vezes deslocados da realidade.

Porém, a partir da década de 1950, e estendendo-se até os anos 1970, começou a se destacar o Movimento da Matemática Moderna que fez um contraponto à concepção acima mencionada. Aqui, o papel pedagógico a ser desempenhado pela Álgebra passa a ser o de fundamentar todo o ensino da Matemática. Nessa direção, prevaleceu a ideia de, ao se justificar as passagens presentes no transformismo algébrico via a introdução de propriedades estruturais das operações, isso bastaria para se capacitar o estudante na identificação dessas estruturas em outros contextos, assim como nas suas aplicações.

Para tanto, os tópicos algébricos foram reorganizados de tal sorte que se ensinassem em primeiro lugar os conjuntos numéricos, suas propriedades estruturais, as sentenças abertas e fechadas, o conjunto-universo e o conjunto-verdade e as equações e inequações do $1^{\circ}$ grau. Só após esse estudo é que seriam abordadas as expressões algébricas, valores numéricos, operações e a fatoração. Por fim, na sequência, seriam introduzidos os novos conteúdos algébricos, isto é, as funções (Fiorentini; Miguel; Miorim, 1993).

Em um terceiro momento, tentou-se fazer uma síntese entre as duas concepções descritas aqui ao se buscar mesclar o caráter de justificação das passagens presentes no transformismo algébrico com o valor instrumental da Álgebra que era a base da Matemática Moderna. O que caracterizou, no entanto, essa nova forma de pensar foi a utilização de recursos analógicos geométricos, portanto visuais. Dito de outra forma, acredita-se aqui que, ao se justificar certas identidades algébricas por meio de construções geométricas, o estudante teria mais facilidades no aprendizado do que uma abordagem estritamente lógico- 
-simbólica. Conscientemente ou não, esse enfoque vai ao encontro de uma das características que envolvem a história da Álgebra, pois, por muito tempo, as justificativas para a resolução de equações algébricas se baseavam em construções geométricas.

Os adeptos dessa concepção, porém, acreditavam que essa etapa geométrico-visual constituiria um primeiro estágio nesse aprendizado e que, a seguir, poder-se-ia apresentar então aos estudantes a abordagem simbólica. Entendemos, porém, que essa passagem se constitui na grande dificuldade do aprendizado, e, recorrendo novamente à história da Álgebra, foi justamente a não percepção de que a Álgebra sobreviveria independentemente de justificativas geométricas que atrasou, de certa forma, o desenvolvimento do que chamamos atualmente de pensamento algébrico-abstrato.

Cabe ressaltar aqui que, dentro dessa concepção, eram normalmente utilizados recursos como balanças e gangorras para a justificação de certas passagens do transformismo algébrico, recorrendo assim a materiais concretos e a leis do equilíbrio físico. Com tudo isso, apesar de se caracterizar de forma distinta, aqui também é conferido o papel principal do ensino às regras algébricas, aproximando-se muito nesse aspecto do transformismo algébrico.

A nosso ver, essas três abordagens parecem incorrer no mesmo equívoco de reduzir o ensino de Álgebra à mera manipulação de regras algébricas.

É justo dizer que essa visão de focar no treinamento de técnicas algébricas ainda prevalece no ensino de Álgebra. Segundo Usiskin (1994), o foco desse ensino na escola básica ainda é medir a capacidade de manejar diversas técnicas operatórias, o que, cabe ressaltar, se constitui em uma habilidade que, por si só, já não é mais tão necessária na vida adulta, dado o desenvolvimento tecnológico atual.

Por outro lado, Aguiar (2014), ao analisar livros didáticos, percebeu que a maioria dos livros do Ensino Fundamental ainda privilegia o ensino de regras e técnicas operatórias, e poucos apresentam propostas voltadas para o desenvolvimento dos conceitos algébricos e do pensamento algébrico. Como fruto desse trabalho, percebe-se que "as inovações aparecem, mas esbarram nos conteúdos arraigados que não perdem o seu espaço no Ensino Fundamental” (Aguiar, 2014, p.286).

Assim, concordamos também com Machado (1991) que defende um ensino que não se concentre tanto na escrita algébrica e mais na compreensão da forma de pensar. Mais especificamente, ele escreve:

Pensamos que a Matemática tem sido ensinada em quase todos os níveis com uma ênfase que consideramos exagerada na linguagem matemática. A preocupação central parece ser escrever corretamente, falar corretamente, em detrimento essencial do papel que a Matemática pode desempenhar quanto ao favorecimento de um pensamento, e um tempo, ordenado e criativo. 
Evidentemente, não se trata de contrapor o pensamento à linguagem; não se pode pretender considera-los desvinculadamente, ou entificá-los, tratando-os um por vez, uma vez que é só na relação entre ambos que se pode aprendê-los. No entanto, em Matemática, com uma frequência muito grande, o pensamento situa-se a reboque da linguagem matemática. Numa parte considerável dos textos, mesmo nos didáticos, o caminho escolhido para a obtenção dos resultados é o mais curto, o mais cômodo ou o esteticamente mais agradável, sempre de um ponto de vista linguístico. (Machado, 1991, p.97-8)

O que se depreende de Machado (1991) é que, para ensinar Álgebra, o desenvolvimento do pensar, em particular o do raciocínio algébrico, deve estar associado com a forma de escrever esse pensamento, e essas habilidades devem ser conjuntamente desenvolvidas sem enfatizar nenhuma delas em detrimento da outra. Deve-se, portanto, vincular os resultados obtidos com a forma de pensar daquele momento de ensino e não com a forma mais fácil de resolução de problemas.

Da mesma maneira, Fiorentini, Miguel e Miorim (1993) discutem essa tendência da crença de que, para o ensino de Álgebra, só por meio da manipulação de sua linguagem específica é que o pensamento algébrico pode se manifestar. Para esses autores, essa é uma abordagem equivocada, pois "essa relação de subordinação do pensamento algébrico à linguagem desconsidera o fato de que, tanto no plano histórico quanto no pedagógico, a linguagem é, pelo menos em princípio, a expressão de um pensamento" (Fiorentini; Miguel; Miorim, 1993, p.85).

Os órgãos governamentais seguem essa mesma tônica ao defender, no que compete ao ensino de Álgebra, a proposta de se evidenciar as habilidades e competências juntamente ao desenvolvimento da forma de pensar algebricamente, como declara os Parâmetros Curriculares Nacionais (PCN):

Embora nas séries iniciais já se possa desenvolver alguns aspectos da álgebra, é especialmente nas séries finais do ensino fundamental que as atividades algébricas serão ampliadas. Pela exploração de situações-problema, o aluno reconhecerá diferentes funções da álgebra (generalizar padrões aritméticos, estabelecer relação entre duas grandezas, modelizar, resolver problemas aritmeticamente difíceis), representará problemas por meio de equações e inequações (diferenciando parâmetros, variáveis, incógnitas, tomando contato com fórmulas), compreenderá a "sintaxe" (regras para a resolução) de uma equação.

Esse encaminhamento dado a álgebra, a partir da generalização de padrões, bem como o estudo da variação de grandezas possibilita a exploração da noção de função nos terceiros e quarto ciclos [atualmente de $6^{\circ}$ ao $9^{\circ}$ ano do Ensino Fundamental]. Entretanto, a abordagem formal desse conceito deverá ser objeto de estudo do ensino médio. (Brasil, 1998, p.50-1) 
Mais adiante, quando os $\mathrm{PCN}$ pretendem orientar os professores para o trabalho com o ensino de Álgebra, é enfatizado que

[...] é mais proveitoso propor situações que levem os alunos a construir noções algébricas pela observação de regularidades em tabelas e gráficos, estabelecendo relações, do que desenvolver o estudo da álgebra apenas enfatizando as "manipulações" com expressões e equações de uma forma meramente mecânica. (ibidem, p.116)

Nos últimos anos, deparamos com a proposta dos órgãos governamentais para incluir o ensino de Álgebra desde os anos iniciais. O Programa Nacional de Alfabetização na Idade Certa (PNAIC) ${ }^{3}$ já havia iniciado essa discussão e colocado algumas ideias sobre o reconhecimento de padrões e regularidades nos anos iniciais visando o ensino de Álgebra. Em 2017, após muita discussão, a Base Nacional Comum Curricular (BNCC) já estabelece os conteúdos mínimos que deverão ser desenvolvidos nos anos iniciais dentro da Unidade Temática Álgebra.

Atualmente, pesquisadores como Ponte, Branco e Matos (2009, p.10) defendem que o grande objetivo do estudo da Álgebra tanto no Ensino Fundamental quanto no Médio é "desenvolver o Pensamento Algébrico nos alunos". Assim, o pensamento algébrico pode ser entendido "como uma forma de estruturação do pensamento - passível de ser desenvolvida desde a Educação Infantil, percorrendo toda a escolaridade - que pressupõe a generalização, transpondo situações particulares a ideias gerais" (Ferreira, 2017, p.20-1).

Resta-nos compreender o que seria esse Pensamento Algébrico e como podemos desenvolvê-lo na sala de aula. Para tanto, nas próximas seções, discutiremos alguns aspectos da história da Álgebra e do pensamento algébrico.

\section{Questões sobre o pensamento abstrato}

Apesar de muitas vezes não nos darmos conta, conceitos abstratos nos rodeiam e interferem em nosso cotidiano. A noção de número é um bom exemplo.

É fato comumente aceito que no início da civilização, assim que os seres humanos deixaram de ser nômades e se fixaram em agrupamentos de pessoas, a necessidade de controle da produção agrícola e pecuária levou à criação de registros numéricos.

Em um primeiro momento, lançou-se mão de alguns outros objetos para fazer essa contagem. Por exemplo, se fosse necessário verificar quantos tonéis de óleo existiam armazenados era comum relacionar, por exemplo, a cada um desses tonéis uma pedra que era separada e colocada em algum outro recipiente, criando-se assim o que chamamos de uma correspondência biunívoca entre tonéis e pedras. A verificação, a posteriori, do número de tonéis ficava imediata: se, em uma próxima contagem sobrassem pedras, isso significava que tonéis foram utilizados, e se faltassem, isso significava que tonéis foram acrescentados ao armazém. Claro está que esse método ainda não indicava que havia números disponíveis. Também, apesar de atualmente podermos caracterizar isso de forma abstrata, ainda esse procedimento não envolvia um grau elevado de abstração, 
pois baseava-se em uma simples ideia de correspondência biunívoca entre dois conjuntos de objetos.

Em um passo posterior, os primeiros registros numéricos específicos representavam não só o número em si, mas também o objeto a ser contado. Dito de outra forma, números estavam atrelados, em um primeiro momento, aos objetos. A maneira como atualmente contamos os objetos demorou ainda um pouco para se consolidar e só veio quando os registros numéricos apareceram desvinculados dos objetos, o que pode ser entendido como um passo rumo à abstração. ${ }^{4}$

Essa sutileza passa despercebida muitas vezes, aprendemos cedo a contar, de certa forma muito automaticamente, e não nos damos conta de que o simples ato de contagem se baseia em um processo mental de abstração.

Quando se aprende a pensar abstratamente? É claro que alguns conceitos abstratos são mais facilmente aceitos que outros e mais naturalmente assimilados em nosso sistema educacional. Por outro lado, o nosso cotidiano está cheio de momentos em que o pensamento abstrato se faz necessário, quer seja quando discutimos política ou religião ou mesmo esporte, quer seja quando buscamos padrões ou analogias em nossas argumentações. $O$ pensamento abstrato não aparece apenas na matemática ou na Álgebra, especificamente, é algo que nos auxilia no desenvolvimento do ato de raciocinar e, por não ser uma característica inerente ao ser humano, ele pode ser desenvolvido de acordo com o meio social em que vivemos.

Nosso objetivo aqui é discutir como a Álgebra, ou mais especificamente a história da Álgebra, pode ser útil no desenvolvimento de um "tipo" de pensamento abstrato. Ao contrário de outras grandes áreas da matemática, a construção da Álgebra como área do conhecimento ao longo dos tempos se deu por um processo de passagem do tratamento de questões concretas a questões abstratas. Esse processo foi gradativo ao longo dos séculos e é isso que gostaríamos de explorar neste texto.

Voltando rapidamente aos números, sabemos que eles não servem apenas para efeito de contagem pura e simplesmente. Há operações embutidas com propriedades que se repetem ou não se considerarmos distintos conjuntos numéricos. A percepção de que há padrões em comum a vários conjuntos, a formulação das propriedades iniciais e de suas consequências, tudo isso se torna parte de um mesmo processo no caminho da abstração. Antes de discutirmos isso em mais profundidade, vamos ver como esse pensamento se dá na educação escolar.

\section{O pensamento algébrico na educação escolar}

Acreditamos na ideia de que o pensamento abstrato, para emergir dentre os cidadãos, precisa de um meio para se desenvolver e ser aprendido. Nesse sentido, e na escola em especial, o ensino de Matemática possui um papel relevante. Faz parte das habilidades matemáticas auxiliar os estudantes a desenvolverem 
tais ferramentas para a sua vida em sociedade. Em especial, a Álgebra pode corroborar se, em seu ensino, o enfoque for o de desenvolver no estudante um pensamento que o auxilie na busca de padrões e analogias quando enfrentar problemas cotidianos.

A isso, poderíamos chamar, em uma primeira aproximação, de pensamento algébrico. No entanto, se nos aprofundarmos, torna-se difícil definir, claramente, o que é de fato o pensamento algébrico. Seria esse uma forma de pensar a partir de um conhecimento algébrico? Quais seriam, então, as habilidades e as características que permeariam indubitavelmente tal pensamento?

Não existe um consenso na literatura a respeito do que significa o pensamento algébrico e o pensar algebricamente.

Blanton e Kaput $(2005$, p.413) definem o pensamento algébrico como "um processo no qual os alunos generalizam ideias matemáticas de um conjunto particular de exemplos, estabelecem generalizações por meio do discurso de argumentação, e expressam-nas, cada vez mais, em caminhos formais e apropriados à sua idade”. No mesmo sentido, Kaput, Blanton e Moreno (2008) consideram que a generalização e a simbolização são os cernes do pensamento algébrico.

Para Ponte, Branco e Matos (2009, p.28), aprender Álgebra significa ser capaz de pensar algebricamente, e que isso inclui o conhecimento das propriedades das operações pois "a identificação destas propriedades e a sua generalização desde os primeiros anos de escolaridade constituem uma base importante para o pensar algebricamente".

Wasserman (2016) salienta que os professores precisam perceber como as propriedades das operações estão sendo trabalhadas pelos estudantes explícita ou implicitamente e precisam saber como problematizá-las.

Blanton e Kaput (2005), p.413 categorizam quatro formas de pensamento algébrico:

[...] o uso da aritmética como domínio da expressão e a formalização da generalização (aritmética generalizada); a generalização de padrões numéricos para descrever as relações funcionais (pensamento funcional); a modelação como um domínio para a expressão e formalização das generalizações; e a generalização sobre sistemas matemáticos abstratos do cálculo e das relações.

Todos esses autores contribuem com visões que, a nosso ver, se complementam no que entendemos ser o pensamento algébrico a ser ensinado nas escolas.

\section{Um pouco da história da Álgebra}

Quando se olha especificamente para a história da álgebra ou, de outro modo, para o desenvolvimento dos métodos algébricos, nota-se que esse acontece em, ao menos, três estágios distintos. Iremos destacar aqui apenas os pontos que mais se relacionam com a nossa discussão sobre o desenvolvimento 
do pensamento algébrico no processo de ensino-aprendizagem da Álgebra na Educação Básica. Para detalhes, indicamos, por exemplo, Hollingdale (2006), Roque (2012) e Struick (1987) que propiciam essas discussões.

Em um primeiro momento, trata-se da resolução de problemas envolvendo equações de primeiro ou segundo graus que são normalmente descritos, problemas e soluções, de forma retórica. Também, como tais equações tinham como motivação, em geral, resolver problemas de cunho geométrico, tanto resolução quanto justificativas, quando as havia, apresentavam esse viés. A própria terminologia usada então refletia, e ainda reflete, isso: raízes quadradas, equações quadráticas e cúbicas são exemplos claros dessa relação.

Observemos também que os números, ainda não compreendidos da forma que hoje os são, embutiam também características geométricas. Não por acaso, números negativos e até mesmo o número zero demoraram a ser aceitos no mesmo nível que os positivos. Mesmo quando, no século XVI, Cardano publicou o seu Ars Magna que tratava de soluções de equações de $3^{\circ}$ e $4^{\circ}$ graus, resultados envolvendo números negativos eram denominados de soluções falsas (Cardano, 2007; Roque, 2012).

Não que os números negativos não tivessem alguma interpretação quando escritos separadamente (como indicando uma dívida), mas o que faltava era uma noção de operacionalidade entre eles, ao contrário do que ocorria quando se pensava no universo dos números positivos. Por exemplo, o que significava o produto de dois números negativos? Cabe ressaltar que, muito provavelmente não por acaso, essa é uma dificuldade que os estudantes dos anos finais do Ensino Fundamental ainda têm.

Interessante notar, a propósito, a contribuição dos matemáticos indianos no que diz respeito a essa questão. Se, por um lado, o sistema posicional decimal indiano (que utilizamos até hoje) chegou à Europa no século XII, por intermédio do matemático Fibonacci, via influência árabe, o mesmo não se pode dizer do entendimento que os indianos tinham dos números negativos e do zero. Alguns matemáticos indianos, como Brahmagupta que viveu no século VII, já tinham uma noção de como operacionalizar tais números. Com um sentido mais utilitário e pragmático no que diz respeito a essas questões, eles também não tinham grandes problemas com operações de números irracionais.

Podemos dizer que a estranheza com números negativos e com o zero ainda iria perdurar por um longo tempo, dividindo opiniões, e isso só seria resolvido quando a matemática já estivesse madura para uma formalização dos conjuntos numéricos e de suas operações.

Um segundo momento é caracterizado pela busca de padrões e regras. A história da matemática, e a da Álgebra, é exemplar nesse aspecto, caracteriza-se pela busca de padrões que definam as estruturas a serem estudadas. Entendemos por isso a busca de elementos e propriedades comuns a estruturas que, em princípio, podem parecer bem distintas. 
Por exemplo, o conjunto dos números inteiros ${ }^{5}$ e o conjunto das funções bijetoras definidas no domínio $\{1,2,3\}^{6}$ possuem comportamentos muito distintos. No entanto, em ambos os conjuntos é possível se definir uma operação. Considerando no conjunto dos números inteiros a operação soma, e no conjunto das funções bijetoras a operação de composição, essas operações compartilham três propriedades (a chamada associatividade, a existência de um elemento neutro dessa operação e a existência de elementos inversos, também relativos a essa operação) e que, por isso, merecem o nome de grupo algébrico (Herstein, 1995). No entanto, existem muitas diferenças entre esses conjuntos: por exemplo, a operação soma considerada no conjunto dos inteiros é uma operação comutativa, pois não importa a ordem dos elementos em que se faz essa soma, mas, no entanto, a operação considerada no conjunto de funções (a composta de funções) não é comutativa.

Sem entrarmos em mais detalhes, o que queremos enfatizar é que conjuntos, mesmo distintos, compartilham padrões matemáticos (operações, propriedades etc.). No caso da Álgebra, um ponto importante para se clarificar os padrões existentes foi o desenvolvimento de uma linguagem própria. Nada mais natural, então, que tal estágio esteja muito ligado ao desenvolvimento das notações matemáticas, que se estabilizaram razoavelmente apenas a partir do século XVI. Mais do que a geometria, a Álgebra dependeu desse desenvolvimento para se fixar como uma área do conhecimento.

O desenvolvimento das notações é, normalmente, dividido em três fases: a retórica, a sincopada e, finalmente, a simbólica. Trabalhar em sala de aula esse percurso a partir de um problema retórico até chegar a uma expressão, digamos, algébrica é bastante salutar e tem sido feito em muitos casos. Mas basta isso para se convencer da importância de boas notações? Acreditamos que é necessária uma integração maior entre esse processo e a busca de padrões.

Com a incorporação de uma simbologia própria substituindo a retórica e, por outro lado, com a necessidade de se achar justificativas que não dependessem tanto da geometria, tornou-se importante olhar as bases em que os métodos algébricos poderiam se fundamentar.

Por sua vez, a formalização dos conjuntos numéricos e de suas propriedades definidoras só se completou nos finais do século XIX e só a partir de então a Álgebra adquiriu finalmente uma fundamentação abstrata que propiciou o seu desenvolvimento como área de pesquisa.

\section{Métodos algébricos}

O significado da palavra Álgebra modificou-se ao longo dos séculos. A rigor, essa palavra, que vem do árabe "al-jabr", só apareceu após o século IX, mas isso não invalida a discussão feita, pois antes muito dos métodos que hoje chamamos de algébricos eram referidos como métodos aritméticos. Aritmética e Álgebra poderiam, nesse sentido, se referir à mesma coisa.

Por todos os estágios pelos quais a Álgebra passou, do mais concreto ao mais abstrato, são usualmente chamados igualmente de Álgebra e, por isso, 
muitas definições são possíveis, mas não iremos entrar nessa polêmica. Assim também não nos interessa aqui nomear qualquer matemático como o pai da Álgebra, pois isso foge e muito de uma discussão na qual gostaríamos de enfatizar aspectos outros que apenas os factuais.

Antes de prosseguirmos, é importante conceituar o que entendemos por métodos algébricos. Eles estão relacionados à manipulação de operações em conjuntos e suas propriedades básicas. Objetivando um melhor entendimento do que temos em mente, poderíamos focar, inicialmente, na fórmula que é usualmente chamada de Bhaskara, ${ }^{7}$ a fórmula que nos propicia achar as soluções de uma equação de segundo grau. Por exemplo, consideremos uma equação genérica

$$
a x^{2}+b x \quad c=0
$$

sendo os coeficientes $a, b, c$ pertencentes a algum conjunto numérico, por exemplo, o conjunto dos números reais. Achar uma solução para tal equação é encontrar um elemento $r$ (nesse mesmo conjunto numérico) tal que, ao substituir $x$ por $r$, a relação

$$
a r^{2}+b r+c=0
$$

seja verdadeira. Por trás dessa sentença matemática estão embutidas, obviamente, duas operações: a da multiplicação (indicadas na notação acima por $r^{2}=r \cdot r$ , $\left.a r^{2}=a \cdot r^{2} \cdot b r-b \cdot r\right)$; e a da adição (por exemplo, $\left.a r^{2}+b r, b r+c\right)$. Essas operações, a depender do conjunto numérico usado, satisfazem certas propriedades que serão descritas mais adiante.

É usual escrever a solução dada pela fórmula de Bhaskara mencionada anteriormente por:

$$
r=\frac{-b \pm \sqrt{b^{2}-4 a c}}{2 a}
$$

sendo os números $a, b, c$ os coeficientes da equação inicial. Observe que, aqui, aparece também a radiciação $(\sqrt{\cdot})$ e, em vista disso, há a necessidade de uma análise sobre a possibilidade de se fazer tal operação considerando o fato de $b^{2}-4 a c$ ser positivo ou não. A operação evidente de divisão que aparece na fórmula pode ser interpretada como uma multiplicação pelo elemento inverso de $2 a$. Sem entrarmos em mais detalhes, o que queremos enfatizar é o fato de estarmos aqui também dependentes das mesmas operações de multiplicação e adição e de certas propriedades (aqui fica claro que precisamos, por exemplo, que os elementos do conjunto em que estamos trabalhando necessitam da propriedade de existência de elementos inversos).

Em suma, o que entendemos por métodos algébricos nessa nossa discussão serão aqueles que envolvem operações em conjuntos predeterminados. A essas operações estão relacionadas propriedades como associatividade, comutatividade, existência de elemento neutro da operação e existência de elementos opostos (ou inversos) também relativos à operação considerada. Propriedades 
distributivas são igualmente importantes se, no conjunto, forem consideradas mais do que uma operação.

Esse processo de percepção de que existem conjuntos nos quais operações são feitas e que dependem necessariamente de certas propriedades é que queremos explorar. Historicamente, a humanidade só se deu conta disso no nível descrito nesta seção após séculos de cálculos e dependeu de um desenvolvimento, em paralelo, de uma linguagem apropriada e de um sistema de numeração adequado do ponto de vista operacional (sistema posicional e, no nosso caso, de base decimal).

\section{Relacionando história e ensino de Álgebra}

Acreditamos que o conhecimento histórico do desenvolvimento de uma ciência, e aqui estamos focando na Álgebra, é essencial para se perceber quais são as bases teóricas em que ela se sustenta. Isso, porém, não quer dizer que o mesmo percurso deva ser percorrido, do ponto de vista didático, em sala de aula.

Para exemplificarmos esse nosso argumento, voltemos um pouco aos números. Como vimos anteriormente, os primeiros números a serem considerados foram os naturais em vista de problemas de contagem. No entanto, uma conceituação formal do que eles são só surgiu nos finais do século XIX com o trabalho de Peano. Nessa mesma direção, os chamados números complexos foram introduzidos (com suas regras algébricas) por Bombelli no século XVI antes mesmo de um entendimento formal dos números reais, o que só viria no século XIX ou mesmo da aceitação global dos números negativos (Hollingdale, 2006).

Didaticamente, porém, faz mais sentido inverter um pouco essa ordem ensinando números naturais, seguidos dos inteiros, racionais, reais e complexos ao invés de se usar a ordem cronológica de suas fundamentações teóricas.

Nessa direção de se discutir a fundamentação que está por trás da Álgebra, poderíamos mencionar a famosa frase "a ordem dos fatores não altera o produto". Dito dessa forma, e sem uma crítica, mesmo que a posteriori, restará ao estudante a certeza de uma regra universal que impõe a igualdade na multiplicação de dois termos independentemente da ordem em que a fazemos. No entanto, após alguns anos, o mesmo estudante, convencido dessa verdade universal, irá deparar com a multiplicação de duas matrizes e, agora sim, a ordem dos fatores irá influenciar o produto.

Referindo-se às matrizes, o próprio produto definido não é algo que se impõe arbitrariamente ou por mero capricho algébrico, mas sim reflete, em sua origem, questões envolvendo sistemas de equações lineares (Coelho, 2016).

Mais do que a mecanicidade da operação de multiplicação de matrizes, o que deveria sobrar é a ênfase do que está por trás desses cálculos. A ordem dos fatores em um produto importa sim, dependendo do produto definido e do conjunto no qual ele está definido. A propriedade que irá nos garantir a igualdade do produto independentemente da ordem dos fatores é chamada de comutatividade e, longe disso, não é uma "verdade universal". 
A discussão desse ponto, isto é, a da validade da propriedade de comutatividade, ganhou importância quando Hamilton, em 1843, definiu uma operação entre os números que ficariam conhecidos como quatérnios ${ }^{8}$ e que não satisfazia a propriedade comutativa. Do ponto de vista histórico, esse é o primeiro exemplo de uma estrutura algébrica coerente com um produto formalmente definido na qual a ordem dos fatores alterava o produto final.

Antes de finalizarmos essa discussão, gostaríamos de analisar outra propriedade algébrica importante. Anteriormente, ao comentarmos a fórmula de Bhaskara, vimos que essa envolvia uma divisão. É possível se ver a divisão de um número $a$ por outro $b$ (não nulo) como sendo o produto desse $a$ pelo elemento inverso de $b$ (por exemplo, o inverso de 2 é $\frac{1}{2}$, o de $\frac{2}{3}$ é $\frac{3}{2}$ e assim por diante). Assim teríamos que

$$
\frac{a}{b}=a \cdot \frac{i}{b}
$$

Isso embute a necessidade de se ter no conjunto em que estamos trabalhando a possibilidade de se inverter elementos. Por exemplo, no conjunto dos números inteiros, só os elementos 1 e - 1 possuem inversos, enquanto que, no conjunto dos reais, todo elemento não nulo possui um inverso. É fácil ver então que a propriedade de existência de inversos em um conjunto é outro exemplo de uma propriedade que não é universal para todos os conjuntos.

Por trás dessa ideia de se olhar a divisão de dois elementos de um conjunto como o produto de um elemento pelo inverso do outro pode ser justificada a regra da divisão de dois números racionais. Lembrando que o inverso do número racional $\frac{a}{b} \operatorname{com} a, b \neq U$ é o número $\frac{b}{a}$. Dessa forma, a divisão de um número racional não nulo $\frac{a}{b}$ por outro também não nulo $\frac{a}{b}$ é dada pela regra

$$
\frac{c / d}{a / b}=\frac{c}{d} \cdot \frac{b}{a}
$$

Apesar de essa regra ser efetivamente ensinada no Ensino Fundamental, acreditamos que nem sempre é feita essa relação acima descrita, o que poderia ser bem adequada.

Vamos retornar um pouco ao conjunto de matrizes quadradas de um determinado tamanho, que é um conjunto no qual podemos definir a multiplicação usual de duas matrizes. Aqui também nem todas as matrizes possuem inversos, isto é, existem matrizes que, ao multiplicarmos por qualquer outra, nunca resultarão na matriz identidade. Por isso, uma divisão de matrizes do jeito que fazemos com os números reais não é possível e isso, talvez, mereça ser explorado em sala de aula.

\section{Considerações finais}

Ao olharmos para os momentos da história da Álgebra descritos neste trabalho percebemos o quanto foi importante para a Álgebra nos dias atuais o 
desenvolvimento de um sistema de numeração posicional; a compreensão do conceito de número; a compreensão, identificação e utilização das propriedades das operações; a capacidade de se identificar padrões nas propriedades para diferentes conjuntos numéricos; a generalização dessas propriedades das operações; o desenvolvimento e a utilização de uma linguagem própria e adequada; a busca pelos padrões ou a identificação da falta deles em várias relações. Em cada momento aqui citado, como exemplos, do desenvolvimento da história da Álgebra ficaram evidenciadas a necessidade e a importância de se reconhecer o padrão existente ou não. Queremos enfatizar que cada momento analisado vai ao encontro do que os educadores matemáticos compreendem sobre desenvolver uma forma de pensar algebricamente (Ponte; Branco; Matos, 2009) e as quatro formas de pensamento algébrico explicitadas por Blanton e Kaput (2005).

Essa aproximação entre a história e a discussão dos educadores só reforça a necessidade de desenvolvermos essas ideias dentro da sala de aula, ao longo de todo o período escolar.

Da mesma forma, concordamos com a National Council of Teachers of Mathematics (NCTM, 2000), organização de referência mundial na área da Educação Matemática, que coloca a Álgebra como um tema transversal que deveria permear todo o período da escolaridade desde os primeiros anos.

Com isso, acreditamos que o ensino, ao invés de tratar inicialmente das técnicas de resolução de problemas propriamente ditas, deveria focar mais na discussão dos significados dos conceitos algébricos. Como dissemos, não defendemos que as técnicas devam ser abandonadas, apenas que não devam ser a preocupação inicial, ou única, para o bom aprendizado. Entender, em um primeiro momento, que existem padrões e propriedades por trás das operações é mais importante do que a mera memorização de técnicas operatórias. Mesmo as fórmulas, quando for o momento de aprendê-las, podem, e devem, ser justificadas a partir dos mesmos parâmetros conceituais.

Entendemos também que, para o processo de ensino e aprendizagem, quer seja de Álgebra, quer seja de qualquer outra área da matemática, o entendimento de como as ideias se desenvolveram ao longo dos tempos é crucial para se discutir conceitos. Pelas características que discutimos neste trabalho, acreditamos que essa correlação é mais necessária e relevante para o ensino.

Dependendo do nível em que o aluno se encontra, ele pode não estar ainda maduro para entender ou assimilar muito do que discutimos. Acreditamos, porém, que, independentemente de qualquer outro fator, o professor deve ter muito claras essas questões para poder desenvolvê-las junto aos alunos.

Concordamos com Fiorentini, Fernandes e Cristóvão (2005) que dizem que o pensamento é uma ação cognitiva do sujeito. Por isso, cabe ao estudante utilizar ou não o pensamento algébrico para resolver uma tarefa de sala de aula, dependendo muito das ferramentas cognitivas que ele possui. Por outro lado, concordamos com Ferreira, Ribeiro e Ribeiro (2017) que, estando a par disso, caberia 
ao professor proporcionar tarefas que estimulassem o pensamento algébrico e não somente proporcionar tarefas que reforcem a utilização de técnicas operatórias.

Notas

1 A BNCC estava prevista na Constituição de 1988, na Lei de Diretrizes e Bases (LDB) de 1996 e no Plano Nacional de Educação de 2014. Esse documento foi elaborado por especialistas de cada área do conhecimento, com a valiosa participação crítica e propositiva de profissionais de ensino e da sociedade civil. O objetivo desse documento é definir o que é essencial para a aprendizagem dos estudantes de todo o país nos diferentes anos de escolaridade e nos diferentes componentes curriculares. A BNCC está disponível em: <http://portal.mec.gov.br/conselho-nacional-de-educacao/base-nacional-comum-curricular-bncc $>$.

$212^{\circ}$ ICMI Study - $12^{\circ}$ International Commission on Mathematical Instruction Study que foi realizado de 9 a 14 de dezembro de 2001 na Universidade de Melbourne, Austrália e tinha como tema "The Future of teaching and learning of algebra", ou seja, "O futuro do ensino e aprendizagem da Álgebra”. Esse encontro reuniu 110 pesquisadores do mundo todo para discutirem sobre o ensino de Álgebra.

3 O PNAIC é um compromisso formal e solidário assumidos pelo governo Federal, do Distrito Federal, dos Estados e dos municípios, desde 2012, para atender a Meta 5 do Plano Nacional da Educação (PNE), que estabelece a obrigatoriedade de "Alfabetizar todas as crianças, no máximo, até o final do $3^{\circ}$ (terceiro) ano do ensino fundamental". Disponível em: <http:// pacto.mec.gov.br/index.php>.

4 Para uma discussão sobre o processo de abstração do significado dos números, ver: Roque (2012, p.40-4 ou p.86-9); Struick (1987, p.10); ou Hollingdale (2006, p.1-2).

5 Para detalhes da definição do conjunto dos números inteiros como grupo ver Herstein (1995, p.41-2).

6 Para ver mais detalhes do conjunto das funções bijetoras que é representado pelo $S_{3}$, ver Herstein (1995, p.108-111).

7 Usaremos essa terminologia que é a mais utilizada para indicar essa fórmula, mesmo reconhecendo a polêmica em torno dela. Indicamos Roque (2012,p.237-242).

8 Para uma discussão sobre as origens dos números quatérnios indicamos Hollind Gale (2006, p.339-342).

\section{Referências}

AGUIAR, M. O percurso da didatização do pensamento algébrico no Ensino Fundamental: uma análise a partir da Transposição Didática e de Teoria Antropológica do Didático. São Paulo, 2014. Tese (Doutorado em Educação) - Faculdade de Educação, Universidade de São Paulo. São Paulo, 2014.

BARBOSA, E.; BORRALHO, A. Pensamento algébrico e explorações de padrões. Disponível em: <apm.pt|files|_Cd_Borralho_Barbosa_4a5752d698ac2.pdf>. Acesso em: 8 fev. 2009.

BLANTON, M.; KAPUT, J. Characterizing a classroom practice that promotes algebraic reasoning. Journal for Research in Mathematics Education, v.36, n.5, p.412-46, 2005 . 
BRASIL. MEC. SEF. Parâmetros Curriculares Nacionais - Matemática: terceiro e quarto ciclos do Ensino Fundamental. Brasília: MEC/SEF, 1998.

CARDANO, G. The rules of Algebra (Ars Magna). Trans. T. Richard Witmer. New York: Dover Publications, Inc., 2007.

COELHO, F. U. Introdução à Álgebra Linear. São Paulo: Editora Livraria da Física, 2016.

FERREIRA, M. C. N. Álgebra nos anos iniciais do Ensino Fundamental: uma análise dos documentos Curriculares Nacionais. REnCIMa, v.8, n.5, p.16-34, 2017.

FERREIRA, M. C. N.; RIBEIRO, M.; RIBEIRO, A. J. Conhecimento matemático para ensinar Álgebra nos Anos Iniciais do Ensino Fundamental. Zetetiké, Campinas, v.25, n.3, p.496-514, set./dez. 2017.

FIORENTINI, D.; FERNANDES, F. L. P.; CRISTÓVÃO, E. M. Um estudo das potencialidades pedagógicas das investigações matemáticas no desenvolvimento do pensamento algébrico. In: SEMINÁRIO LUSO-BRASILEIRO DE INVESTIGAÇÕES MATEMÁTICAS NO CURRÍCULO. 2005. Portugal. Disponível em: <http://www. educ.fc.ul.pt/docentes/Jponte/seminario_lb.htm>. Acesso em: 13 ago. 2016.

FIORENTINI, D.; MIGUEL, A.; MIORIM, M. A. Contribuição para um Repensar... a Educação Algébrica Elementar. Pro-Posições, Revista Quadrimestral da Faculdade de Educação-Unicamp. Campinas, v.4, n.1[10], p.78-91, 1993.

HERSTEIN, I. N. Abstract Algebra. 3.ed. s. 1.: John Wiley \& Sons, Inc., 1995.

HOLlingDAlE, S. Makers of Mathematics. New York: Dover Publications, Inc., 2006.

KAPUT, J.; BLANTON, M.; MORENO, L. Algebra from a symbolization point of view. In: KAPUT, J.; CARRAHER, D. W.; BLANTON, M. L. (Ed.) Algebra in the early grades. New York: Lawrence Erlbaum Associates, 2008. p.19-55.

LINS, R. C.; GIMENEZ, J. Perspectivas em aritmética e álgebra para o século XXI. Campinas: Papirus, 2001.

MACHADO, N. J. Matemática e realidade: análise dos pressupostos filosóficos que fundamentam o ensino de matemática. 2.ed. São Paulo: Cortez, 1991.

NATIONAL COUNCIL OF TEACHERS OF MATHEMATICS - NCTM. Principles and standards for school mathematics. Reston, VA: NCTM, 2000.

PONTE, J.; BRANCO, N.; MATOS, A. Álgebra no Ensino Básico. Ministério da Educação, Portugal. Direção Geral de Integração e de Desenvolvimento Curricular (DGIDC). Portugal, 2009

RIBEIRO, A. J. Analisando o desempenho de alunos do Ensino Fundamental em álgebra, com base em dados do SARESP. São Paulo, 2001. Dissertação (Mestrado em Educação Matemática) - Pontifícia Universidade Católica. São Paulo, 2001.

RIBEIRO, A. J.; CURY, H. N. Álgebra para a formação do professor: explorando os conceitos de equação e de função. Belo Horizonte: Autêntica Editora, 2015. (Col. Tendências em Educação Matemática).

ROQUE, T. História da matemática: uma visão crítica, desfazendo mitos e lendas. Rio de Janeiro: Zahar, 2012.

SILVA, V. A. D. Relação com o saber na aprendizagem matemática: uma contribuição 
para a reflexão didática sobre as práticas educativas. Revista Brasileira de Educação, v.3, n.37, jan./abr. 2008.

STACEY, K.; CHICK, H. Solving the problem with Algebra. In: STACEY, K. et al (Ed.) The Future of teaching and learning of algebra: The $12^{\text {th }}$ ICMI Study. Dordrecht: Kluwer Academic Publishers, 2004. p.1-20.

STRUIK, D. J. A concise history of Mathematics. 4.ed.rev. New York: Dover Publications, Inc., 1987.

USISKIN, Z. Concepções sobre a álgebra da escola média e utilizações das variáveis. In: COXFORD, A. F. E SHULTE, A. P. As ideias da álgebra. The National Council of Teachers of Mathematics. Trad. Hygino H. Domingues. São Paulo: Atual, 1994.

WASSERMAN, N. H. Abstract algebra for algebra teaching: Influencing school mathematics instruction. Canadian Journal of Science, Mathematics and Technology Education, v.16, n.1, p.28-47, 2016.

RESUMO - O ensino de Álgebra tem se restringido a questões técnicas e operacionais, deixando de lado, muitas vezes, o desenvolvimento de conceitos e do pensamento algébrico. Acreditamos que esse enfoque está por trás das deficiências diagnosticadas em várias pesquisas e avaliações governamentais. Neste texto, apresentamos como os conceitos que foram relevantes para o desenvolvimento da álgebra ao longo dos séculos podem e devem participar do processo de ensino da álgebra.

PALAVRAS-CHAVE: Ensino de Álgebra, Pensamento algébrico, História da álgebra, Pensamento abstrato.

ABSTRACT - The teaching of Algebra has been restricted to technical and operational issues, often leaving aside the development of concepts and so-called algebraic thinking. We believe that this approach underlies the deficiencies diagnosed in various government surveys and assessments. In this text, we present how concepts that were relevant to the development of Algebra over the centuries can and should participate in the process of teaching Algebra.

KEYWORDS: Algebra teaching, Algebraic thinking, History of Algebra, Abstract thinking.

Flávio Ulhoa Coelho é professor titular do Instituto de Matemática e Estatística (IME) da Universidade de São Paulo (USP) e pesquisador do Instituto de Estudos Avançados da USP (IEA-USP). @ - fucoelho@ime.usp.br

Marcia Aguiar é professora adjunta do Centro de Matemática, Computação e Cognição (CMCC) da Universidade Federal do ABC (UFABC).

@ - marcia.aguiar@ufabc.edu.br

Recebido em 6.3.2018 e aceito em 10.4.2018.

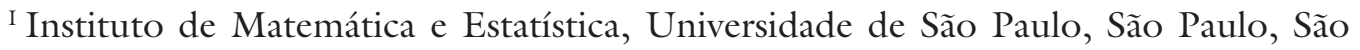
Paulo, Brasil.

II Centro de Matemática, Computação e Cognição, Universidade Federal do ABC, Santo André, São Paulo, Brasil. 
